\title{
Evaluation of Modified Alvarado Score in the Diagnosis of Acute Appendicitis In Patients Admitted At Rajendra Institute of Medical Sciences, Ranchi
}

\author{
Dr. Utkrisht Kant ${ }^{1}$, Dr. Shiva Thakur ${ }^{2}$, Dr. Vinay Pratap ${ }^{3}$ \\ ${ }^{I}$ Senior Resident, Department of General Surgery, Rajendra Institute of Medical Sciences, Ranchi. \\ ${ }^{2}$ Junior Resident, Department of General Surgery, Rajendra Institute of Medical Sciences, Ranchi. \\ ${ }^{3}$ Associate Professor, Department of General Surgery, Rajendra Institute of Medical Sciences, Ranchi.
}

\begin{abstract}
:
Introduction: Acute appendicitis, the most common surgically correctable cause of abdominal pain, the diagnosis of which remains difficult in many instances and is essentially clinical. However a decision to operate based on clinical suspicion alone can lead to removal of a normal appendix in 15-30\% cases. Several diagnostic scoring systems have been devised as an aid to the early diagnosis of acute appendicitis and to reduce the incidence of negative appendicectomy. One such scoring system was described by Alvarado and later modified by Kalan et al. The present study is attempted to evaluate the efficiency of modified Alvarado score in pre-operative diagnosis of acute appendicitis.

Material and Method: A 75 consecutive patients suspected of acute appendicitis that were admitted, investigated and treated were taken for the study. After detailed examination and investigations a modified Alvarado score was applied to these patients.

Results: The result of the study showed that high score in men (7-9) had a sensitivity of 92\% respectively, where as in females it had sensitivity of $76.4 \%$. The score (5-6) in men \& females had a sensitivity of $60 \%$ and $50 \%$ respectively.

Conclusion: The high scores in modified Alvarado score is dependable aid in the early diagnosis of acute appendicitis in men and children but it's not true as far as women are concerned. Ultrasonography of abdomen is a useful tool in avoiding negative appendicectomy rates particularly in children.
\end{abstract}

Keywords: Acute Appendicitis, Modified Alvarado Score

\section{Introduction}

Acute appendicitis is the most common surgically correctable cause of abdominal pain, the diagnosis of which remains difficult in many instances. Some of the signs and symptoms can be subtle to both the clinician and the patient and may not be present in all instances. Arriving at the correct diagnosis is essential, however, a delay may allow progression to perforation and significantly increased morbidity and mortality. Incorrectly diagnosing a patient with appendicitis although not catastrophic often subjects the patient to an unnecessary operation. ${ }^{1}$

The diagnosis of acute appendicitis is essentially clinical; however a decision to operate based on clinical suspicion alone can lead to removal of a normal appendix in 15-30\% cases. The premise that it is better to remove a normal appendix than to delay diagnosis doesn't stand up to close scrutiny, particularly in the elderly. A number of clinical and laboratory based scoring systems have been devised to assist diagnosis. The most commonly used is the Alvarado score and equally its modifications. ${ }^{2}$

Modified Alvarado Score consists of three symptoms, three signs and a laboratory finding as described by Alvarado ${ }^{3}$ and later modified by Kalan et al. ${ }^{4}$ Patients with a score of 1-4 who are not considered likely to have acute appendicitis will be observed and not operated unless for compelling reasons to do so. Those with scores between 5-6 will be considered to have possible diagnosis of acute appendicitis, but not convincing enough to warrant immediate surgery and these patients will be monitored at 4 hourly intervals and if within 24 hours of observation their score become $\geq 7$ or their clinical features are convincing enough to warrant surgery, then irrespective of their scores, appendicectomy will be performed. All patients with scores 7 to 9 will be considered to have either probable or definite diagnosis of acute appendicitis and will be considered for appendicectomy in first instance. ${ }^{5}$

\section{Materials And Methodology}

This study was conducted on patients presenting with pain in the right lower quadrant of Abdomen, lasting fewer than 7 days who after clinical examination were provisionally diagnosed to have acute appendicitis and were admitted in Rajendra Institute of Medical Sciences, Ranchi 


\section{Inclusion criteria:}

1. Patients with provisional clinical diagnosis of acute appendicitis.

\section{Exclusion criteria}

1. Patients of age less than or equal to 12 years

2. Patients with generalised peritonitis due to appendicular perforation

3. Patients with appendicular mass or abscess.

A total of 75 consecutive cases of suspected acute appendicitis who were admitted, investigated and treated were taken for the study. After detailed examination and investigations a modified Alvarado score was applied to each case.

\section{Following decisions were taken:}

Cases with score of 1-4 were observed and not operated and were followed up after discharge for next six months for development of acute appendicitis.

Cases with score 5-6 were observed for next 24 hours for revision of scoring. If score became $>7$ or their clinical condition was highly suspicious of acute appendicitis as decided by treating surgeon they were subjected for appendicectomy.

All patients who were considered for appendicectomy underwent ultrasonography of abdomen primarily to rule out other conditions mimicking acute appendicitis.

Patients with score of 7-9 who were considered candidates for appendicectomy were assessed again after ultrasonography. If any other conditions mimicking acute appendicitis was found in them, they were not operated and were considered as false positive cases.

\section{Results}

Group - 1: 10 patients were in first group (1-4) who were not considered likely to have appendicitis. They were observed and were treated conservatively. Discharged after 2-3 days and were followed up every month for 6 months and none of them required surgery.

Group - II : 23 patients were in second group (5-6), 7 were operated upon clinical suspicion of high probability of acute appendicitis.

Rest of the 16 cases were not operated, were observed and discharged after 3 to 4 days of stay in hospital and followed up every month for 6 months and none of them required surgery during the period of observation. Of the 7 patients, whose score was 5-6 who were operated, 5 were males and 2 were females.

Table - I: Distribution of cases according to modified Alvarado Score (5-6)

\begin{tabular}{|c|c|c|c|c|}
\hline Category of cases & $\begin{array}{l}\text { No. of cases } \\
\text { operated }\end{array}$ & $\begin{array}{l}\text { No. of cases } \\
\text { with } \\
\text { Appendicitis }\end{array}$ & $\begin{array}{l}\text { No. of cases } \\
\text { without HP } \\
\text { Appendicitis }\end{array}$ & $\begin{array}{l}\text { Proportion } \\
\text { of true } \\
\text { positive }\end{array}$ \\
\hline Male $(\mathrm{n}=17)$ & 5 & 3 & 2 & $60 \%$ \\
\hline Female $(\mathrm{n}=6)$ & 2 & 1 & 1 & $50 \%$ \\
\hline Total $(\mathrm{n}=23)$ & 7 & 4 & 3 & $57.1 \%$ \\
\hline
\end{tabular}

3 out of 5 males and 1 out of 2 females, had acute appendicitis. The overall negative appendicectomy rate of patients with scores $<6$ is $42.9 \%$.

Group - III : Of the 42 patients in third group, 38 patients underwent appendicectomy. 4 female patients on subjecting for ultrasonography of abdomen had other pathology mimicking acute appendicitis and they didn't under go appendicectomy.

Table - II: Distribution of cases according to modified Alvarado Score (7-9)

\begin{tabular}{|c|c|c|c|c|}
\hline Category of cases & $\begin{array}{l}\text { No. of cases } \\
\text { operated }\end{array}$ & $\begin{array}{l}\text { No. of cases } \\
\text { with HP } \\
\text { Appendicitis }\end{array}$ & $\begin{array}{l}\text { No. of cases } \\
\text { without HP } \\
\text { Appendicitis }\end{array}$ & $\begin{array}{l}\text { Proportion of } \\
\text { true positive }\end{array}$ \\
\hline Male $(n=17)$ & 25 & 23 & 2 & $92 \%$ \\
\hline Female $(n=6)$ & 17 & 13 & 0 & $76.4 \%$ \\
\hline Total $(n=23)$ & 42 & 36 & 2 & $85.7 \%$ \\
\hline
\end{tabular}

Two patients had pelvic inflammatory diseases, and two patient had ruptured ectopic pregnancy. 36 cases out of 42 cases had acute appendicitis. The sensitivity of modified Alvarado score of $>7$ was $85.7 \%$ (proportion of true positive). The sensitivity was highest among males i.e., 92\% while in females, it was $76.4 \%$. 
Negative appendicectomy rates was highest among females (23.6\%), where as in case of males it was $8 \% .2$ males patients with normal appendix had Meckel's diverticulitis.

\section{Discussion}

The result of present study showed that a high score $(>7)$ in men was a satisfactory aid in the early diagnosis of acute appendicitis, the overall sensitivity in men with scores $>7$ was $92 \%$, with a negative appendicectomy rate of $8 \%$. But in females the negative appendicectomy rates were quite high in groups with score of 5 to 6 as well as 7 to 9 . The negative appendicectomy rate in the above groups being 50\% and 23.6\% respectively. Sensitivity of acute appendicitis $92 \%$ for males in the present study with score of 7 to 9 correlates well with the figures of studies by Kalan $\mathrm{M}^{4}$, Rich AJ, Talbot D, Cunliffe WJ (who have reported 93\%) and P.K. Bhattacharjee, T. Chowdhary, D.Roy ${ }^{5}$ (who have reported 94.1\%).

Sensitivity of acute appendicitis $76.4 \%$ for females in the present study with score of 7 to 9 correlates well with the figures of studies by Kalan $\mathrm{M}^{4}$, Rich AJ, Talbot D, Cunliffe WJ (who have reported 67\%) and P.K. Bhattacharjee, T. Chowdhary, D.Roy ${ }^{5}$ (who have reported $71.9 \%$ ). The overall sensitivity of acute appendicitis being $85.7 \%$ in the present study with score of 7 to 9 correlates well with the figures of studies by Kalan $\mathrm{M}^{4}$, Rich AJ, Talbot D, Cunliffe WJ (who have reported 83.7\%) and P.K. Bhattacharjee, T. Chowdhary, D.Roy ${ }^{5}$ (who have reported $82.7 \%$ ).

\section{Conclusion}

From the present study it may be concluded that high scores (7-9) in modified Alvarado score is dependable aid in early diagnosis of acute appendicitis in men but the same is not true as far as women are concerned, because of other conditions mimicking appendicitis like pelvic inflammatory disease, ruptured ectopic pregnancy. Ultrasonography of abdomen is a useful tool in avoiding negative appendicectomy rates particularly in females.

\section{References}

[1]. Douglas S Smink, David I Soybel. “Appendix and Appendectomy” Chapter 21.In Manigot's abdominal operations, Michacel J Zinner, Stanely W Ashely McGraw Hill; 11th edition, 2007; 589-612.

[2]. P Ronan O' Connel. "The Vermiform Appendix". Chapter 67. In Bailey and Love's - Short practice of surgery, Norman S Williams, Christopher J.K. Bulstrode, P Ronan O' Connel; London. Arnold: 25th edition. 2008; 1204-18.

[3]. Alvarado A. "A practical score for the early diagnosis of acute appendicitis". Ann Emerg Med, 1986; 15:557-65.

[4]. Kalan M. et Al. "Evaluation of the modified Alvarado score in the diagnosis of acute appendicitis, a prospective study". Ann R Coll Surg Engl 1994; 76:418-9.

[5]. Bhattacharjee PK, Chowdhury T, Roy D. "Prospective evaluation of Modified Alvarado score for diagnosis of acute appendicitis." J Indian Med Assoc, May 2002; 100 (5): 310-1, 314. 